\title{
Convivência com a pré-eclâmpsia: desvelando olhares de puérperas
}

\section{Association with pre-eclampsia: unveiling of mothers' looks}

\author{
Taysa Vieira de Almeida ${ }^{1}$, Mônica Cecília Pimentel de Melo $^{2}$, Ramon José Leal de Morais ${ }^{3}$
}

1. Enfermeira obstétrica do Hospital Regional Ruy de Barros Correia, Arcoverde-PE. 2. Docente em Enfermagem da Universidade Federal do Vale do São Francisco (UNIVASF), Petrolina-PE...3. Coordenador da Residência de Enfermagem do Hospital Dom Malan/Instituto de Medicina Integral Prof. Fernando Figueira (IMIP), Petrolina-PE.

\section{Resumo}

Introdução: As síndromes hipertensivas classificam-se em graus variados e têm potencial destaque em exigir um acompanhamento rigoroso no prénatal. $O$ estudo pretendeu analisar a vivência de puérperas do Hospital Dom Malan/ IMIP de Petrolina-PE na trajetória da pré-eclâmpsia. Métodos: Estudo qualitativo, exploratório e descritivo, realizado no Hospital Dom Malan/IMIP, em Petrolina, Pernambuco, Brasil, com 20 puérperas que tiveram diagnóstico de pré-eclâmpsia em gestação referente ao puerpério atual. A coleta foi realizada no período de abril a setembro de 2014, por meio de um roteiro de entrevista semiestruturado, com tratamento do material empírico segundo a Análise do Discurso. Aprovado pelo Comitê de Ética e Deontologia em Estudos e Pesquisas da Universidade Federal do Vale do São Francisco, sob protocolo no 0005/200214. Resultados e discussões: Emergiram o pouco conhecimento das puérperas sobre a pré-eclâmpsia; a história pregressa como um contribuinte no desfecho dos resultados, desvelando, a partir daí, sentimentos de angústia, medo e ansiedade frente à incerteza do estado de saúde das mulheres. Isto posto, os discursos pontuaram a necessidade de um seguimento criterioso do pré-natal de modo abrangente e esclarecedor. Conclusões: 0 estudo evoca a necessidade de os profissionais de saúde priorizarem nas consultas pré-natais, a escuta qualificada e as informaç̧ões de educação em saúde, na busca de melhores resultados de cuidado e adesão ao tratamento.

Palavras-chave: Gestação. Pré-Eclâmpsia. Pré-Natal. Saúde da Mulher

\section{Abstract}

Introduction: Hypertensive disorders are classified in varying degrees; they have the potential feature of requiring close monitoring during prenatal care. The study analyzes the experience of mothers of Dom Malan Hospital / IMIP of Petrolina in the history of pre-eclampsia. Methods: Qualitative, exploratory and descriptive study was conducted at Hospital Dom Malan / IMIP, in Petrolina, Pernambuco, Brazil, with 20 mothers who were diagnosed with preeclampsia in pregnancy for the current postpartum. Data collection was conducted from April to September 2014, through a semi-structured interview guide, with treatment of the empirical material through Discourse Analysis. Approved by the Ethics Committee and Ethics Studies and Research of the Federal University of São Francisco Valley under Protocol 0005/200214. Results and discussion: There emerged the little knowledge of mothers on preeclampsia; previous history as a contributor in the outcome of the results, revealing, from there, feelings of anxiety, fear and anxiety when facing uncertainty of the health status of women. That said, the speeches punctuated the need for strict follow-up of prenatal comprehensively and enlightening. Conclusions: The study refers to the need for health professionals to prioritize the prenatal visits, the qualified hearing and health education information in the search for better outcomes of care and treatment adherence.

Keywords: Pregnancy. Pre-Eclampsia. Prenatal. Women's Health

\section{INTRODUÇÃO}

A hipertensão arterial sistêmica (HAS) é o agravo que mais comumente complica a gravidez, atingindo de $5 \%$ a $10 \%$ das gestações, caracterizando-se como uma das principais causas de morbimortalidade materna e perinatal. O diagnóstico é feito por meio de medida seriada dos níveis pressóricos, definindose por hipertensão na gravidez valores absolutos de pressão arterial (PA) sistólica $\geq 140 \mathrm{mmHg}$ e/ou diastólica $\geq 90 \mathrm{mmHg}$, em pelo menos duas verificações próximas ${ }^{1-4}$.

As síndromes hipertensivas classificam-se em graus variados de acometimento e gravidade, sendo elas: a hipertensão crônica; a gestacional; a pré-eclâmpsia; a eclâmpsia, e por fim, a préeclâmpsia superposta à HAS crônica ${ }^{4}$.

Entre as síndromes hipertensivas mais comuns destaca-se a préeclâmpsia (PE) como terceira causa de mortalidade materna, acometendo 5 a $7 \%$ das gestantes no mundo, sendo a maior ocorrência registrada nos países em desenvolvimento. Em cerca de $80 \%$ dos casos, a pré-eclâmpsia se manifesta depois de 34 semanas de gestação, próximas ao termo, configurando altas taxas de mortalidade e morbidade perinatal ${ }^{5-7}$.

No Brasil, segundo o Ministério da Saúde, a hipertensão gestacional é responsável por cerca de $35 \%$ dos óbitos maternos, com uma taxa de 140 a 160 mortes maternas $/ 100.000$ nascidos vivos $^{8}$.

Os sinais clássicos observados na pré-eclâmpsia são: hipertensão após 20 semanas de gestação acompanhada de proteinúria, com valores de $300 \mathrm{mg}$ ou mais em urina de $24 \mathrm{~h}$, em gestantes anteriormente normotensas4. Observa-se, em muitos casos, que a primeira manifestação da pré-eclâmpsia consiste em alterações nos níveis pressóricos, de início assintomáticas. Isso explica o fato de $12 \%$ das gestantes não referirem queixas ${ }^{9}$.

Correspondência: Taysa Vieira de Almeida. Rua: Aprígio Estevão Tavares, no36. Centro. Arcoverde-PE. CEP: 56506-650. . E-mail: taysaxto@hotmail.com Conflito de interesse: Não há conflito de interesse por parte de qualquer um dos autores.

Recebido em: 2 Maio 2015; Revisado em: 12 Maio 2015; Aceito em: 26 Maio 2015. 
Nesse contexto, o acompanhamento rigoroso durante o prénatal tem por objetivo atender às reais necessidades das gestantes, de modo a proporcionar, em tempo oportuno, a redução das taxas de mortalidade materna e perinatal ${ }^{1,8}$.

Logo, mediante a ocorrência de casos de pré-eclâmpsia e das altas taxas de mortalidade materna e perinatal levantou-se como objeto de estudo: vivência de puérperas na trajetória da pré-eclâmpsia. Múltiplos são os fatores que estão envolvidos na ocorrência da pré-eclâmpsia na gestação, dentre eles os imunológicos, os genéticos e os ambientais, bem como, da qualidade da assistência e da adesão da gestante ao acompanhamento pré-natal. Isto posto, buscou-se responder à seguinte questão de pesquisa: Como as puérperas atendidas no Hospital Dom Malan/Instituto de Medicina Integral Prof. Fernando Figueira (IMIP), de Petrolina-PE, experienciam a préeclâmpsia?

Como objetivos pretendeu-se analisar a vivência de puérperas do Hospital Dom Malan/IMIP na trajetória da pré-eclâmpsia; compreender os enfrentamentos e adversidades de puérperas acerca da pré-eclâmpsia; analisar as percepções de puérperas quanto à doença; delinear as condutas profissionais e repercussões da pré-eclâmpsia, a partir da vivência de puérperas.

Pelo destaque que a pré-eclâmpsia possui, do ponto de vista da morbimortalidade materna, acredita-se, que com esse estudo poderá ser possível um maior desvelamento da patologia, em um cenário que parte das experiências de puérperas, no intuito de estabelecer abordagens mais integrais de assistência à saúde da mulher, na promoção de melhores resultados de cuidado, adesão ao tratamento e autocuidado.

\section{MÉTODOS}

Estudo qualitativo exploratório ${ }^{10}$. Ocorreu no Hospital Dom Malan/Instituto de Medicina Integral Prof. Fernando Figueira (IMIP), em Petrolina, Pernambuco, Brasil, com puérperas, internadas na unidade do alojamento conjunto, que tiveram diagnóstico de pré-eclâmpsia em gestação referente ao puerpério atual.

Os critérios de inclusão foram: idade menor, igual ou superior a 18 anos, boas condições clínicas e psicológicas que possibilitassem o estabelecimento de diálogo e decidissem participar voluntariamente da pesquisa. A opção de incluir as menores de 18 anos deveu-se ao fato da ocorrência considerável de préeclâmpsia na adolescência ${ }^{9}$. Optou-se por fazer a abordagem somente no puerpério por ser mais favorável e confortável para a realização das entrevistas, uma vez que as puérperas já tinham concluído o tratamento para a pré-eclâmpsia.

A amostra do estudo para definição do número de pessoas obedeceu ao critério da saturação das informações ${ }^{11}$. Desse modo, a saturação foi atingida na 12a entrevista, mas outras 8 entrevistas foram coletadas para se identificar a repetição dos resultados, totalizando 20 entrevistas.

A coleta do material empírico foi realizada no período de abril a setembro de 2014 , por meio de um roteiro de entrevista individual e semiestruturado. Para proceder à coleta, as participantes foram esclarecidas anteriormente e convidadas a participar da pesquisa. Caso estivessem de acordo, assinavam o Termo de Consentimento Livre e Esclarecido (TCLE) e dava-se início às entrevistas, sendo estas gravadas, mediante autorização prévia das participantes. A presença do acompanhante foi garantida a todas as depoentes, conforme a Lei no 11.108 de 7 de abril de 2005. Para tanto, no intuito de evitar interferências no momento da entrevista, foi explicado aos acompanhantes que eles não poderiam intervir no momento da entrevista ${ }^{12}$.

Os dados foram analisados por meio da técnica de Análise do Discurso (AD). Esta estratégia de pesquisa se apropria do discurso, e não do conteúdo do texto. A proposta da AD não tem a intenção em descobrir algo novo, apenas realiza uma nova interpretação do contexto composto pela seguinte formulação: ideologia, história e linguagem ${ }^{13}$.

O estudo foi aprovado pelo Comitê de Ética e Deontologia em Estudos e Pesquisas da Universidade Federal do Vale do São Francisco, sob protocolo no 0005/200214. Em concordância com a resolução 466/2012, relacionada à pesquisa com seres humanos, o anonimato foi garantido adotando-se nomes de pedras preciosas para a identificação das puérperas, seguida da caracterização de cada entrevistada, conforme a seguinte ordem: idade, raça, estado civil, escolaridade, paridade e parto atual.

\section{RESULTADOS E DISCUSSÕES}

A partir da análise do material empírico emergiram seis categorias temáticas de acordo com a ideia expressa nos discursos das entrevistadas.

\section{Compreendendo a pré-eclâmpsia: partejando ao lado do inimigo}

Em se tratando da compreensão da pré-eclâmpsia (PE), os discursos mostraram que as puérperas não tinham a concepção do que era a pré-eclâmpsia, ou possuíam uma ideia vaga sobre sua ocorrência. Porém, os seus relatos revelaram que nas últimas semanas de gestação, próximas ao parto, passaram a ter sinais e sintomas preditores da pré-eclâmpsia, tais como alterações dos níveis pressóricos, não controladas por medicação; cefaleia e edema.

As puérperas referiram também que só tiveram conhecimento do diagnóstico na internação, ou no momento da realização do parto cesáreo ou no pós-parto, já na Unidade de Terapia Intensiva - UTI. Uma vez que as pacientes no pós-parto imediato são encaminhadas à UTI para utilização do sulfato de magnésio por vinte e quatro horas, concluindo assim, a terapêutica de estabilização do quadro clínico, é que são encaminhadas ao 
alojamento conjunto.

Disseram que era normal, [...]. A partir de 8 meses passaram para mim (metildopa). Já tava sentindo dor, e os sintomas (do parto). [...]. Depois que eu tava na UTI, foi que disseram o que eu tinha. (Cristal, 32 anos, parda, casada, ensino médio completo, terceira gestação parto cesáreo).

[...] já se aproximando de eu ganhar o bebê. Comecei alterando a pressão, ficando inchada, sentindo muita dor de cabeça. [...] fui ao posto; aí, o posto passou remédio [...], só que não conseguiu controlar. Aí, me mandaram para cá [...]. Já foram logo preparando para fazer cesárea. (Ágata, 25 anos, parda, casada, ensino fundamental incompleto, quarta gestação, parto cesáreo).

[...] quando eu passei no postinho, aí, eles mediram e tava alta a pressão. Já estava com nove meses. No dia quando eu tava para fazer a cesárea, aí, foi que o médico falou. (Safira, 19 anos, indígena, casada, ensino médio incompleto, primeira gestação, parto cesáreo).

Eu pensava que era só com mulheres que tivessem pressão alta durante toda gestação. Nunca imaginei que poderia ser só no final da gestação. [...]. (Pedra Luz, 36 anos, parda, união consensual, ensino médio completo, terceira gestação, parto cesáreo).

Ainda em relação à ocorrência da pré-eclâmpsia, observa-se, nos discursos abaixo, o relato do acontecimento desta no período do parto. Nota-se também nas falas, a expressão de espanto, medo e angústia das puérperas frente ao desconhecimento do diagnóstico.

[...] A pressão ter subido de repente em uma paciente que nunca teve pressão alta!! [...] Eu estava sentindo as dores já para ter a bebê. [...]. (Turquesa, 37 anos, parda, união consensual, ensino superior incompleto, quarta gestação, parto normal).

[...] porque eu já tinha tido um começo. Eu estava grávida dela, já tinha tido, já estive aqui na UTI internada, [...] Por isso, fiquei com medo. (Turmalina, 24 anos, parda, união consensual, ensino básico incompleto, quarta gestação, parto cesáreo).

A hipertensão arterial é responsável por cerca de $10 \%$ das complicações gestacionais e, entre elas destaca-se a préeclâmpsia como a principal causa de morbimortalidade materna e perinatal. A incidência de PE é maior em mulheres jovens e nulíparas ${ }^{3,6}$.

O aparecimento dos sinais clínicos como hipertensão, proteinúria e edema ocorrem na segunda metade da gravidez de modo lento e insidioso. As pacientes que apresentam préeclâmpsia podem manifestar vários sinais clínicos, tanto de ordem materna, como fetal, sendo que o agravo pode ocorrer durante a gestação, no parto ou no pós-parto ${ }^{6,8,9}$. Contudo, corroborando com o que foi apresentado neste estudo pelas puérperas, em mais de $80 \%$ dos casos descritos na literatura, a pré-eclâmpsia tende a se manifestar após 34 semanas de gestação.

No que diz respeito ao desconhecimento das puérperas sobre a pré-eclâmpsia durante o pré-natal, estudos mostram que as pacientes somente obtêm conhecimento sobre sua situação por meio da internação hospitalar devido à gravidade clínica ou pelo parto iminente, o que ocasiona reações de surpresa, choque, ansiedade e medo em relação ao diagnóstico, em conformidade com o que foi mensurado nos resultados aqui elencados ${ }^{14}$.

Um estudo realizado no Canadá avaliou a perspectiva de mulheres e dos prestadores de cuidados acerca da qualidade do pré-natal. $O$ estudo evidenciou que a informação dos prestadores de cuidados foi relatada pelas mulheres como aspecto fundamental na assistência ao pré-natal de qualidade, pois, segundo elas, a informação transmitida sem códigos, de modo claro, faz que se sintam envolvidas e responsáveis por seu processo de cuidado ${ }^{15}$.

Os profissionais de saúde mencionados no estudo anterior, também concordaram que a informação concedida à mulher sobre o seu processo de saúde faz que ela se torne mais confiante no profissional e ajude na tomada de decisão em todo o seu cuidado. Um relacionamento de confiança pode contribuir para que a mulher não se sinta intimidada em questionar suas prováveis dúvidas, como também pode reduzir a sua ansiedade e contribuir para resultados positivos ${ }^{15}$.

\section{Prevenindo as complicações: agir a partir de qual momento?}

Os discursos revelaram que para cada entrevistada houve uma trajetória que conduziu a diferentes intervenções em momentos distintos, conforme as falas abaixo:

Eu fui fazer a consulta, [final da gestação] a pressão tava 150/100mmHg. Aí, o médico disse que era bom internar logo, porque podia ser que eu não aguentasse, [...]. (Jaspe, 24 anos, parda, casada, ensino fundamental incompleto, terceira gestação, parto cesáreo).

[...] porque disse que minha pressão estava muito alta. Tava dando os remédios e não tava controlando. [...] estava com falta de ar, pressão alta. (Água Marinha, 18 anos, negra, solteira, ensino fundamental completo, primeira gestação, parto cesáreo).

[...] Eu estava com seis meses. Comecei a inchar um 
pouquinho, aí, a enfermeira me pediu aquele teste de proteinúria. [...] como eu estava inchando e ganhei peso muito rápido durante a semana, que isso era sinal da pré-eclâmpsia. [...]. Então, com 34 semanas a pressão subiu para $150 / 100 \mathrm{mmh}$, foi quando eu aqui e tomei medicamento em casa, mas também não mudou nada, a pressão continuou oscilando [...]. (Pedra Luz, 36 anos, parda, união consensual, ensino médio completo, terceira gestação, parto cesáreo).

O seguimento criterioso da gestante na primeira abordagem do pré-natal como anamnese, exame físico, histórico familiar e pessoal, são bons preditores da pré-eclâmpsia 6 . A detecção e o seguimento atento no pré-natal são fundamentais para estabelecer o diagnóstico precoce e o tratamento adequado em tempo oportuno ${ }^{9}$.

Embora haja controvérsias, o Ministério da Saúde (MS) recomenda que todas as pacientes com diagnóstico de préeclâmpsia, independente da gravidade do quadro clínico, mesmo os casos leves, devem ser hospitalizadas para acompanhamento em gestação de alto risco, tendo em vista a avaliação do bem-estar materno-fetal ${ }^{4}$.

A orientação do MS para pacientes que cursam com préeclâmpsia na gravidez, referindo aumento rápido de peso, edema facial ou outros sintomas característicos da doença, requerem acompanhamento mais rigoroso da pressão arterial (PA) e mensuração de proteinúria, conforme relatado na fala de Pedra Luz. Caso os níveis pressóricos comecem a se elevar, a paciente deverá ser reavaliada em, no máximo, três dias e redefinir a conduta a partir do diagnóstico ${ }^{1}$.

O tratamento anti-hipertensivo, em casos de hipertensão aguda, está indicado quando a pressão arterial diastólica é $>105 \mathrm{mmHg}$ e a pressão arterial sistólica é $>160 \mathrm{mmHg}$, com vistas a prevenir complicações cardiovasculares e cerebrovasculares, evitando também quedas súbitas de PA. O objetivo é manter a pressão de perfusão cerebral materna e o fluxo sanguíneo uteroplacentário ${ }^{1,9}$.

O tratamento definitivo da PE é a finalização da gestação, mas essa decisão não é tão simples de ser tomada, devido ao fato de ela nem sempre ser benéfica para o feto. Por isso, devem-se avaliar as condições materno-fetais para se indicar a conduta mais adequada 4 .

Um dos temas que vem sendo abordado com frequência na literatura são os casos de morbidade grave durante o ciclo gravídico puerperal, principalmente, os casos extremamente graves, conhecido como near miss, quadro que se caracteriza por apresentar complicações fatais para as mulheres, mas que sobrevivem devido ao bom cuidado hospitalar ou ao acaso ${ }^{16}$.

Faz-se necessário que os profissionais deem maior atenção não somente à morte materna em si, mas aos distintos graus e condições de adoecimento que podem levar à morte materna, no intuito de se inteirar mais sobre os problemas relacionados à gravidez, ao parto e ao puerpério, e estabelecer condutas que minimizem os resultados desfavoráveis ${ }^{16}$.

\section{Indicativo da história pregressa como fator contribuinte}

Nos discursos abaixo, emergiram dois aspectos diferentes em que as entrevistadas atribuíram como ocorrência para a préeclâmpsia, sendo um, em relação à ocorrência da enfermidade em gestação anterior, com óbito do feto por asfixia, e o outro, relacionado ao histórico familiar.

[...] da primeira gravidez eu tive, [...]. Aí, o outro bebê morreu, [...] por asfixia, [...] mas, a enfermeira disse que podia ter e podia não ter [...]. (Cristal, 32 anos, parda, casada, ensino médio completo, terceira gestação, parto cesáreo).

[...] minha mãe, ela teve eclâmpsia mesmo, e eu corria o risco de ter [...]. (Pedra Luz, 36 anos, parda, união consensual, ensino médio completo, terceira gestação, parto cesáreo).

A ocorrência da pré-eclâmpsia, bem como das síndromes hipertensivas como um todo, são um assunto de grande relevância na saúde pública por suas implicações materno-fetais; no entanto, sua etiologia ainda permanece desconhecida ${ }^{3,17}$.

Alguns estudos relacionam a ocorrência de PE a uma combinação de fatores genéticos, imunológicos e ambientais que ocasionam em uma falha no momento de invasão trofoblástica das arteríolas espiraladas, culminando com a redução da perfusão uteroplacentária. Essa funcionalidade abalada na adaptação placentária desencadeia uma cascata de eventos celulares e moleculares que vão determinar a lesão endotelial nos vasos dentro da circulação materna, ocasionando pré-eclâmpsia ${ }^{3,17}$.

Múltiplos são os fatores que podem estar relacionados ao risco de uma gestante desenvolver pré-eclâmpsia; entre eles: gestação múltipla, história de pré-eclâmpsia em gestações anteriores, extremos de idade fértil, familiares de primeiro grau que apresentaram pré-eclâmpsia, hipertensão crônica, entre outros, confirmando os resultados encontrados neste estudo ${ }^{9,17}$.

\section{Cuidados profiláticos implementados no pré-natal: orientações fornecidas}

Os principais relatos das puérperas com relação aos cuidados a que foram orientadas a ter, no pré-natal, para prevenir a préeclâmpsia, foram a dieta e a redução do sal, conforme relatos abaixo.

[...] só comer mais verduras, diminuir o sal. (Cristal, 32 anos, parda, casada, ensino médio completo, terceira gestação, parto cesáreo).

[...] Ter a dieta direitinho também, porque tudo podia 
ter complicação. (Jaspe, 24 anos, parda, casada, ensino fundamental incompleto, terceira gestação, parto cesáreo).

Evitar comer negócio salgado, essas coisas assim, negócio de fritura, com muito óleo. [...]. (Turmalina, 24 anos, parda, união consensual, ensino básico incompleto, quarta gestação, parto cesáreo).

[...] só evitar sal [...] (Pedra Luz, 36 anos, parda, união consensual, ensino médio completo, terceira gestação, parto cesáreo).

Na literatura, ainda não existem medidas profiláticas efetivas que possam impedir as manifestações clínicas da pré-eclâmpsia. Não obstante, estudos revelam que a suplementação de algumas substâncias, como o cálcio e a administração de aspirina possam trazer benefícios moderados para as gestações de alto risco, na prevenção da PE e de suas consequências ${ }^{3,18}$.

Diferentemente aos achados desse estudo, ensaios clínicos incluídos na Biblioteca Cochrane avaliaram um grupo de gestantes com restrição de sal na dieta e outro com dieta normal, não evidenciando diferenças estatísticas significativas com relação ao risco, entre os grupos, para o desenvolvimento da pré-eclâmpsia18. Todavia, existe um outro postulado que orienta a utilização da dieta hipossódica, uma vez que a redução na ingesta de sal promove queda dos níveis séricos de sódio com consequente diminuição da reatividade vascular e diminuição da $\mathrm{PA}^{19}$.

Já no discurso de Pérola, observou-se a associação do fumo e do estresse como fatores deletérios para a ocorrência de préeclâmpsia.

Para não fumar, não beber, não ter raiva, não se preocupar, pois era perigoso. (Pérola, 37 anos, parda, união consensual, ensino fundamental incompleto, nona gestação, parto cesáreo).

Segundo estudos epidemiológicos, o risco relativo de desenvolvimento da pré-eclâmpsia é maior em situações de estresse. Postula-se que os fatores emocionais influenciam no sistema imunológico, facilitando a deposição de imunocomplexos, dificultando, assim, a placentação normal. Como consequência à baixa oxigenação placentária, surgem os radicais livres, os quais ocasionam a lesão endotelial ${ }^{19}$.

De acordo com outros ensaios clínicos mencionados na Biblioteca Cochrane, realizou-se um comparativo entre gestante com risco moderado de desenvolver pré-eclâmpsia, mas que possuíam repouso regular diário, das que tinham atividade normal. O estudo evidenciou redução considerável no risco de desenvolver pré-eclâmpsia nas gestantes que tiveram de quatro a seis horas de repouso por dia ${ }^{18}$.

\section{Impressões do pré-natal no serviço público de saúde}

As principais impressões relatadas pelas puérperas em relação à consulta pré-natal foram que as consultas precisam ser mais informativas e esclarecedoras.

Ser mais esclarecedor. Qual a alimentação correta para você evitar [...]. (Turquesa, 37 anos, parda, união consensual, ensino superior incompleto, quarta gestação, parto normal).

Eles não conversam, não explicam. (Ágata, 25 anos, parda, casada, ensino fundamental incompleto, quarta gestação, parto cesáreo).

[...] Explicar as coisas direito. Eles não explicam nada não. (Água Marinha, 18 anos, negra, solteira, ensino fundamental completo, primeira gestação, parto cesáreo).

Eles só falaram que não podia comer muita besteira. Só que eles não explicaram o porquê. [...]. (Rubi, 26 anos, parda, casada, ensino médio completo, segunda gestação, parto cesáreo).

O pré-natal tem por objetivo garantir o desenvolvimento saudável do período gestacional no intuito de permitir gravidezes e partos seguros, sem causar impactos deletérios para a saúde materno-infantil4. Sua assistência deve abranger programas de educação que se voltem para dar esclarecimentos sobre as prováveis complicações que possam ocorrer no ciclo gravídicopuerperal, com vistas à prevenção e à intervenção precoce ${ }^{1}$.

A percepção das gestantes quanto à gestação de risco ainda é um fator que as predispõe ao estresse psicológico, pois o enquadramento neste grupo, por vezes, causa medo, ansiedade e incertezas do cotidiano. Estudos revelam que a inclusão da gestante de risco no conhecimento do processo de sua situação de saúde, faz com que ela se torne mais responsável por si e pela saúde de seu filho ${ }^{14}$.

O estabelecimento de diálogo no processo gravídico-puerperal torna-se uma importante ferramenta terapêutica que possibilita a mulher o acesso à autonomia, confiança e segurança, mediante seu estado de saúde, bem como, permite estabelecer melhor interação entre a equipe de saúde e a família ${ }^{16}$.

A informação é um direito inalienável dos indivíduos, e portanto, elemento fundamental da prática e cuidado em saúde ${ }^{16}$. Nesse sentido, o estudo pretende chamar a atenção dos profissionais, atuantes nos diferentes níveis de atenção à saúde, a darem maior atenção às necessidades das pacientes e permitirem que estas também sejam protagonistas do seu processo de saúde.

Ainda em relação às impressões do pré-natal, Pedra Luz traz no seu discurso a necessidade de haver maior interação entre os membros a equipe de saúde.

[...] a gente é atendido o tempo todo por enfermeira. [...] eu ia atrás do médico também. Então, eu acho que deveria haver uma parceria maior entre a médica mais a enfermeira, em relação a gestante. (Pedra 
Luz, 36 anos, parda, união consensual, ensino médio completo, terceira gestação, parto cesáreo).

A visão do trabalho em equipe, na Estratégia Saúde da Família (ESF), está pautada, principalmente, no aspecto da integralidade do cuidado em saúde, ou seja, por meio desta, busca-se, de modo ampliado, compreender as necessidades de saúde da população atendida, incluindo os aspectos objetivos e subjetivos. Para isso, torna-se necessária a ação dos diversos profissionais no intuito de se integrar o conhecimento profissional, com vistas à resolutividade do caso, de modo individualizado e sob um olhar terapêutico que valorize a integração interdisciplinar ${ }^{20}$.

\section{Condições de assistência materno infantil nos municípios}

Os discursos abaixo evidenciaram a migração das pacientes, tanto da atenção primária, quanto da terciária, por falta de recursos humanos e equipamentos, na busca pela resolutividade de seu caso.

[...] Eu passei no Hospital de Andorinhas; de Andorinhas eu vim para o Hospital de Bonfim e de Bonfim, eu vim para cá, [...] porque lá não tinha os aparelhos, equipamentos para fazer uma cesariana. (Rubi, 26 anos, parda, casada, ensino médio completo, segunda gestação, parto cesáreo).

Onde eu moro, não tem posto. O posto mais próximo também não tem médico. Aí, eu peguei e vim aqui. (Jaspe, 24 anos, parda, casada, ensino fundamental incompleto, terceira gestação, parto cesáreo).

Eu saí do posto João Paulo II, fui para a Clise. $\mathrm{Na}$ Clise não tem UTI. De lá, me encaminharam para cá. (Cristal, 32 anos, parda, casada, ensino médio completo, terceira gestação, parto cesáreo).

Petrolina é o município sede da 4o macrorregião de saúde do estado de Pernambuco, Brasil, que abrange as regiões do Submédio do Vale do São Francisco e do Araripe, envolvendo a VII, VIII e IX regiões de saúde. As macrorregiões de saúde são arranjos territoriais que têm por objetivo organizar os serviços de média e alta complexidade desses territórios. Essa modalidade de atenção à saúde se constitui no principal nível de referência para o atual modelo de assistência na alta complexidade ${ }^{21}$.

O Hospital Dom Malan/IMIP, localizado no centro da cidade de Petrolina, pertence à Rede Estadual de Saúde de Pernambuco. Caracteriza-se como sendo um centro de referência para 55 cidades no sertão de Pernambuco e Bahia. Possui uma UTI pediátrica, a única do Vale do São Francisco e uma UTI materna, única no interior do Nordeste ${ }^{22}$.

No ano de 2011 foi implantada a primeira Central de Regulação Interestadual do País, na 4ㅇ macrorregião de saúde de Pernambuco, com vistas a organizar o acesso aos serviços de alta complexidade das especialidades: cardiovascular, oncologia, materno-infantil e urgência/emergência ${ }^{21}$. No entanto, o que se observa é que a rede de saúde ainda possui muitas lacunas em seu sistema, pois se percebe por meio dos discursos que as pacientes migraram por várias unidades para poder obter a resolutividade de seu caso. Isto tem implicado em consequências para as mulheres, deixando-as mais ansiosas e receosas mediante a morosidade em solucionar o estado de saúde de cada uma.

Neste sentido, torna-se necessário que a gestão pública tome conhecimento da situação atual da rede de atenção à saúde, no intuito de avaliar as necessidades de cada serviço e estudar melhor seu fluxograma, com vistas a propor mais investimentos e melhores soluções para as mais variadas situações da rede, para assim, otimizar a demanda de saúde reprimida, bem como, realizar os encaminhamentos para os devidos serviços de referência.

\section{CONCLUSÃO}

O estudo permitiu identificar que as puérperas não tinham conhecimento sobre a ocorrência da pré-eclâmpsia ou possuíam uma ideia vaga do que pudesse ser a enfermidade. A ausência ou a inadequação da informação gerou nas pacientes angústia, medo e ansiedade frente à incerteza de seu estado de saúde.

Os discursos pontuaram que durante o pré-natal houve orientação por parte dos profissionais de saúde, acerca dos cuidados que as puérperas deveriam seguir para o desfecho gestacional saudável. Porém, enfatizaram a forma como estas informações foram dispensadas durante o acompanhamento gravídico-puerperal, ressaltando a necessidade de consultas pré-natais mais esclarecedoras.

Observa-se ainda que as pacientes também manifestaram descontentamento em relação à assistência hospitalar, no que diz respeito a falta de diálogo e informação sobre o seu processo de saúde, pois como foi mencionado no estudo, muitas delas só tiveram conhecimento do diagnóstico no momento da internação, ou na iminência do parto ou no pós-parto.

Nesse sentido, ressalta-se a importância do estabelecimento da informação e da consulta dialogada em saúde, com vistas a esclarecer à paciente sobre o seu real estado de saúde e tornála protagonista neste processo. Destaca-se ainda, a necessidade de uma consulta pré-natal mais detalhada, com anamnese, exame físico, histórico familiar e pessoal, com incentivo às boas práticas de saúde, no intuito de prevenir possíveis complicações e intervir precocemente.

Diante do exposto, torna-se evidente a necessidade de os profissionais de saúde, de todos os níveis de atenção à saúde, lançarem um olhar mais atento às necessidades de cada paciente, de modo que as visualizem de maneira holística. 0 estudo também fornece subsídios para priorizar a consulta prénatal no que diz respeito a investir na escuta qualificada e nas informações de educação em saúde, com vistas a melhorias dos resultados de cuidado, adesão ao tratamento e consequente redução da mortalidade materna e perinatal. 


\section{REFERÊNCIAS}

1. Ministério da Saúde, Secretaria de Atenção a Saúde, Departamento de Ações Programáticas Estratégicas. Gestação de alto risco: manual técnico [Internet]. 5. ed. Brasília: Ministério da Saúde; 2010. [acesso 2012 Set 10]. Disponível em: http://bvsms.saude.gov.br/bvs/publicacoes/manual_tecnico_gestacao_alto_ risco.pdf.

2. Souza NL, Araujo ACPF, Costa ICC. Significados atribuídos por puérperas às síndromes hipertensivas da gravidez e nascimento prematuro. Rev Esc Enferm USP [Internet]. 2011 [acesso 2013 Set 04]; 45(6):1285-92. Disponível em: http://www.scielo.br/pdf/reeusp/v45n6/v45n6a02.pdf.

3. Federação Brasileira das Associações de Ginecologia e Obstetrícia, Comissões Nacionais Especializadas Ginecologia e Obstetrícia. Manual de orientação gestação de alto risco [Internet]. Rio de Janeiro: FEBRASCO; 2011 [acesso 2014 Ago 02]. Disponível em: http://febrasgo.luancomunicacao.net/wp-content/ uploads/2013/05/gestacao_alto-risco_30-08.pdf.

4. Ministério da Saúde, Secretaria de Atenção a Saúde, Departamento de Atenção Básica, Atenção ao pré-natal de baixo risco [Internet]. Brasília: Ministério da Saúde; 2012 [acesso 2013 Set 10]. Disponível em: http://189.28.128.100/dab/ docs/portaldab/publicacoes/caderno_32.pdf.

5. Oliveira CA, Lins CP, Sá RAM, Chaves $H$, Netto, Bornia RG, Silva NR, et al. Síndromes hipertensivas da gestação e repercussões perinatais. Rev Bras Saúde Matern Infant [Internet]. 2006 Jan-Mar [acesso 2013 Fev 03]; 6(1):93-8. Disponível em: http://www.scielo.br/pdf/rbsmi/v6n1/a11v6n1.pdf.

6. Brandão AHF, Lopes APBM, Cabral MA, Scala FD, Leite HV, Cabral ACV. Predição de pré-eclâmpsia: a realidade atual e as direções futuras. Femina [Internet]. 2010 Set [acesso 2013 Ago. 20]; 38(9):487-91. Disponível em: http:// files.bvs.br/upload/S/0100-7254/2010/v38n9/a487-491.pdf.

7. Organização Mundial de Saúde. Mortalidad materna [Internet]. Nota descriptiva 2014 Maio [acesso 2013 Set.10]; (348). Disponível em: <http:// www.who.int/mediacentre/factsheets/fs348/es/index.html>.

8. Moura MDR, Castro MP, Margotto PR, Rugolo LMSS. Hipertensão arterial na gestação: importância do seguimento materno no desfecho neonatal. Comun Ciências Saúde [Internet]. 2011 [acesso 2013 Set. 04]; 22(Sup 1):S113-S20. Disponível em: http://bvsms.saude.gov.br/bvs/artigos../hipertensao_arterial_ gestacao.pdf.

9. Lacerda IC, Moreira TMM. Características obstétricas de mulheres atendidas por pré-eclâmpsia e eclâmpsia. Acta Sci Health Sci [Internet]. 2011 [acesso 2013 Ago. 20]; 33(1):71-6. Disponível em: http://periodicos.uem.br/ojs/index.php/ ActaSciHealthSci/article/viewFile/7711/7711. doi: 10.4025/actascihealthsci. v33i1.7711

10. Minayo MCS. O desafio do conhecimento: pesquisa qualitativa em saúde. 10. ed. São Paulo: Hucitec; 2007.

11. Vanderlei LCM. Introdução às técnicas qualitativas de pesquisa aplicadas em saúde. Rev Bras Saude Mater Infant [Internet]. 2010 [acesso 2015 Mai 29];.10(2):265-66. Disponível em: http://www.scielo.br/scielo.php?script=sci_ arttext\&pid=S1519-38292010000200014

12. Brasil. Lei no 11.108 , de 7 de abril de 2005 . Dispõe sobre a garantia às parturientes do direito à presença de acompanhante durante o trabalho de parto, parto e pós-parto imediato, no âmbito do Sistema Único de Saúde - SUS [Internet]. Diário Oficial [da] República Federativa do Brasil. 2005 abr 7 [acesso 2013 Nov 06]. Disponível em: http://www.planalto.gov.br/ccivil_03/_Ato20042006/2005/Lei/L11108.htm.

13. Caregnato RCA, Mutti R. Pesquisa qualitativa: análise de discurso versus análise de conteúdo. Texto Contexto Enferm [Internet]. 2006 [acesso em 2013 Nov. 20]; 15(4):679-84. Disponível em: http://www.scielo.br/pdf/tce/v15n4/ v15n4a17. doi: http://dx.doi.org/10.1590/S0104-07072006000400017.

14. Silva EF, Cordova FP, Chachamovich JLR, Záchia SA. Percepções de um grupo de mulheres sobre a doença hipertensiva específica da gestação. Rev Gaúch Enferm [Internet]. 2011 Jun [acesso 2013 Nov 10]; 32(2):316-22. Disponível em: http://www.scielo.br/scielo.php?pid=S1983-14472011000200015\&script=sci arttext. doi: http://dx.doi.org/10.1590/S1983-14472011000200015

15. Sword W, Heaman MI, Brooks S, Tough S, Janssen PA, Young D, et al. Women's and care providers' perspectives of quality prenatal care: a qualitative descriptive study. BMC Pregnancy and Childbirth linternet]. 2012 [acesso 2015 Mar 20];12:29. Disponível em: http://www.biomedcentral.com/14712393/12/29. doi: 10.1186/1471-2393-12-29. PubMed PMID 22502640.

16. Carvalheira APP, Tonete VLP, Parada CMGL. Feelings and Perceptions of Women in the Pregnancy-Puerperal Cycle Who Survived Severe Maternal Morbidity. Rev Latino-Am Enfermagem [Internet]. 2010 Nov-Dez [acesso 2015 Mar. 25];18(6):1187-94. Disponível em: http://www.scielo.br/pdf/rlae/ v18n6/20.pdf. PubMed PMID 21340285.

17. Amorim MMR, Souza ASR, Katz L, Coutinho I. Predição da pré-eclâmpsia baseada em evidências. Femina [Internet]. 2008 Out [acesso 2015 Fev. 05]; 36(10):627-34. Disponível em: http://www.febrasgo.org.br/site/wp-content/ uploads/2013/05/Femina_outubro2008-627.pdf.

18. Amorim MMP, Souza ASR. Prevenção da pré-eclâmpsia baseada em evidências. Femina [Internet]. 2009 [acesso $2015 \mathrm{Fev}$ 05]; 37(1):47-52. Disponível em: http://disciplinas.stoa.usp.br/pluginfile.php/204814/mod_folder/content/0/ Preven\%C3\%A7\%C3\%A3o\%20da\%20pr\%C3\%A9-ecl\%C3\%A3mpsia\%20 baseada\%20em\%20evid\%C3\%AAncias.pdf?forcedownload=1.

19. Zugaib, M. Zugaib obstetrícia. 2. ed. São Paulo: Manole; 2012.

20. Araújo MBS, Rocha PM. Trabalho em equipe: um desafio para a consolidação da estratégia de saúde. Ciênc Saúde Coletiva [Internet]. 2007 [acesso 2015 Fev. 05]; 12(2):455-64. Disponível em: http://www.scielosp.org/scielo. php?pid=S1413-81232007000200022\&script=sci_arttext.

21. Secretaria de Saúde do Estado de Pernambuco (Brasil). Plano diretor de regionalização [Internet]. Recife: Secretaria de Saúde do Estado de Pernambuco; 2011 [acesso 2015 Fev. 5]. Disponível em: http://portal.saude.pe.gov.br/sites/ portal.saude.pe.gov.br/files/pdrconass-versao_final1.doc_ao_conass_em_ jan_2012.pdf.

22. Pernambuco (Brasil). Secretaria Estadual de Saúde de Pernambuco. Hospital Dom Malan. Recife, 2010 [acesso 05 Nov. 2013]. Disponível em: http://portal. saude.pe.gov.br/unidades-de-saude-e-servicos/secretaria-executiva-deatencao-saude/hospital-dom-malan

\section{Como citar este artigo/How to cite this article:}

Almeida TV, Melo MCP, Morais RJL. Convivência com a pré-eclâmpsia: desvelando olhares de puérperas. J Health Biol Sci. 2015 Abr-Jun; 3(2):99-105. 